Please quote as: Kummer, T.-F.; Leimeister, J. M. \& Bick, M. (2012): On the Importance of National Culture for the Design of Information Systems. In: Business \& Information Systems Engineering, Ausgabe/Number: 6, Vol. 4, Erscheinungsjahr/Year: 2012. Seiten/Pages: 317-330. 


\section{On the Importance of National Culture for the Design of Information Systems}

Culture can be defined as shared values and behavior patterns and is highly relevant for the development of socio-technical systems. Publications in this domain show substantial heterogeneity due to the variety of related problems and questions, as well as the focus on different types of culture. In this paper we develop a comprehensive framework for the design of culturally sensitive information systems that enables us to structure previous publications. Based on this framework, a literature review is conducted to investigate which meeting points of national culture and the elements of system development have thus far been addressed. We explore existing knowledge related to the different aspects of culturally sensitive design of information systems and identify areas where further research is needed in order to enhance corresponding design knowledge.

\section{The Authors}

Dr. Tyge-F. Kummer ( $₫)$ Institute of Information Systems School of Business and Economics Humboldt-Universität zu Berlin Spandauer Straße 1 10178 Berlin Germany tyge.kummer@hu-berlin.de

Prof. Dr. Jan Marco Leimeister Insitute of Information Management University of St. Gallen Mueller-Friedberg-Strasse 8 9000 St. Gallen

Switzerland JanMarco.Leimeister@unisg.ch and

Chair for Information Systems Kassel University

Pfannkuchstr. 1

34121 Kassel

Germany

leimeister@uni-kassel.de

Prof. Dr. Markus Bick Business Information Systems ESCP Europe Campus Berlin Heubnerweg 8-10 14059 Berlin Germany mbick@escpeurope.eu
Received: 2011-11-22

Accepted: 2012-09-06

Accepted after two revisions by

Prof. Dr. Armin Heinzl.

Published online: 2012-11-08

This article is also available in German in print and via http://www. wirtschaftsinformatik.de: Kummer T-F, Leimeister JM, Bick M, (2012) Die Bedeutung von nationaler Kultur für die Gestaltung von Informationssystemen. WIRTSCHAFTSINFORMATIK. doi: 10.1007/s11576-012-0340-4.

Electronic Supplementary Material The online version of this article (doi: 10.1007/s12599-012-0236-2) contains supplementary material, which is available to authorized users.

(c) Springer Fachmedien Wiesbaden 2012

\section{Introduction}

National culture - in the sense of shared values and norms of behavior of individuals in a country (Straub et al. 2002) - has had a major influence on the design of information systems (Leidner and Kayworth 2006). Examples include, among other things, the success of different design websites, mobile devices and mobile services in the western world and Asia
(Ishii 2004; Choi et al. 2005). Differences in respective national cultures are of vital importance for the design of information systems, thus providing the desired functionality, facilitating the use of the systems and avoiding problems with acceptance (Ishii 2004; Choi et al. 2005; Leidner and Kayworth 2006). Furthermore, different moral concepts can be exercised by system designers, especially on international development projects, and thus lead to problems that jeopardize a successful introduction (Winkler et al. 2007; Keil et al. 2007; Tan et al. 2003; Yuan and Vogel 2006).

The cultural influence on information systems has been studied since the 1970s (Gallivan and Srite 2005). Leidner and Kayworth (2006) have identified a total of 85 research projects that deal with the influence of national and organizational culture on information systems. These can be assigned to six topic areas (Culture and IS Development, Culture, IT adoption and diffusion, Culture, IT Use and Outcomes, Culture, IT Management and Strategy, IT's Influence on Culture, IT Culture). A total of ten articles can be assigned to the particularly relevant topic "Culture and Development IS". However, the field of "IT adoption and diffusion" can also be assigned to articles considered in the process of designing information systems from a cultural perspective. The observance of cultural requirements for systems and products can significantly influence the success, and these are therefore of particular relevance (Marcus and Gould 2000). Main goal thus is to explore 
the present knowledge on the role of culture in the design of information systems. Given the high heterogeneity of the research in this subject area, it requires a dedicated analysis of the literature to systematically work out which results exist and which research questions remain unanswered.

This paper presents research findings concerning the importance of national culture in the design of information systems, along with a dedicated framework that is structured and compacted. Based on this, research gaps will be worked out and the following research questions will be answered:

1. What results have been achieved and what research methods were used?

2. What research potentials exist and how can they be developed?

3. What theoretical models are used to connect the national culture with the design of information and communication systems?

In the following, the underlying regulatory framework is explained (Sect. 2), after that the methodology of the analysis is given (Sect. 3). The corresponding results of the study are presented in Sect. 4, and in Sect. 5 the implications are discussed. The paper concludes with a summary of achieved results and their value for the research community of business information systems engineering (BISE).

\section{Framework Development}

The main scientific object of the BISE research community is the information system itself. It builds a foundation for the framework (Sect. 2.1), and, in our case, helps to classify the papers that we identify during the literature review. Additionally, we need to explain the underlying understanding of culture (Sect. 2.2). Finally, we develop the framework that connects the design of information systems with culture.

\subsection{Design of Information Systems}

The design orientation defines a central stream, especially within the Germanspeaking BISE research community (Fettke et al. 2010). Using innovative techniques, for example, in the form of methods, models, and software prototypes, the aim is to develop artifacts that can be used to solve practical problems (Becker 1995; Hevner et al. 2004). The system design requires a design entity that performs the design. These are, in general, people (e.g., business analyst, programmer), who, by means of a design technique (e.g., Unified Modeling Language - UML) pursue a design objective (e.g., mapping of business processes). In contrast, the design object involves socio-technical systems. The approach by Sydow (1988) stipulates that the design object is a structured set of tasks (e.g., business processes) and technologies (e.g., Business Process Management System) which comprise not only the technical subsystem, but also members (e.g., users) and roles (such as key account management) that comprise the social subsystem. The human and mechanical components (subsystems) serve a specific task (Heinrich et al. 2011; n.a. 2011). Figure 2 shows these relationships, as well as the relationship between design subject and design object schematically.

The design of information systems is divided into single phases/work steps (due to complexity reduction), which help to structure the development process as well as to support corresponding project management with procedure models (e.g., Stahlknecht and Hasenkamp 2004). In particular, the phases that are typically connected with the design of information systems need to be taken into account for the development of the regulatory framework for the literature review.

\subsection{Culture and Cultural Dimensions}

In cultural research, it are the differences and similarities of people from different cultural backgrounds that are analyzed in order to gain a better understanding of the processes associated with cultural effects (Straub et al. 2002). Here, culture is indeed addressed comprehensively, but a unique and universal definition does not exist, as is evident in Kroeber and Kluckhohn's (1952, pp. 77 ff.) identification of 162 different definitions of culture. Culture is a complex and elusive phenomenon that includes both the orientation patterns and the associated mechanisms of mediation and expressions (Schreyögg 1999). In this context, shared norms and common values in many definitions are a central feature (Straub et al. 2002). This understanding of culture is also taken as a basis for this paper.

Various approaches are represented in cultural research that relate not only to different definitions but also to different reference objects or layers and areas of application. Below, we summarize these approaches to three broad categories of cultural research: national, organizational and group. The focus in this article is placed on national culture, as the design subject as well as the social subsystem on the design object level are usually humans that are predominantly influenced by their national environment. As a result, we first distinguish national culture from the other two types of culture (organizational and group) and then demonstrate their interactions. The aim is to develop a suitable distinction to highlight cross-references to other types of culture. We thus reflect on three main types, using a cultural research perspective. References to information system design are then worked out in due course.

\subsubsection{National Cultural Research}

In national cultural research, attitudes and behavioral differences between people from different countries are examined. The most common contribution in this area has been provided by Hofstede (1980). Based on the data collected by a questionnaire at IBM, Hofstede identified four cultural dimensions (power distance, individualism versus collectivism, masculinity versus femininity, and uncertainty avoidance) that set employees in different countries apart from one another. Hofstede later added the dimension time orientation (Hofstede and Bond 1998). His work was criticized in particular because of the age of the used data and the exclusive consideration of IBM employees, who may have caused a distortion of the organizational culture (Erez and Earley 1993, p 55; House et al. 1997). Nevertheless, Hofstede's work in the field of BISE continues to be cited frequently (Gallivan and Srite 2005; Leidner and Kayworth 2006).

Apart from Hofstede, other authors have identified cultural dimensions. For example, Hall and Hall (1990) have identified four alternative dimensions: spatial understanding, contextual reference, understanding of time and speed of a message. Other constructs have been presented by Schwartz (1992) and Hampden-Turner and Trompenaars (1993). As part of the Global Leadership and Organizational Behavior Effectiveness (GLOBE) study, an attempt has also been made to compensate the weaknesses 
Fig. 1 Models for the conceptualization of culture: Schein (2004) as example for the organizational culture, Karahanna et al. (2005) as example for different cultural layers and their structure

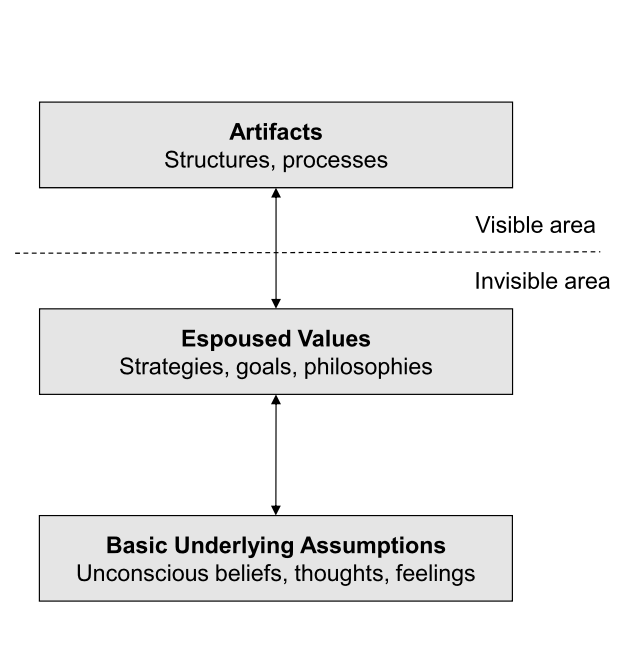

Levels of culture by Schein (2004)

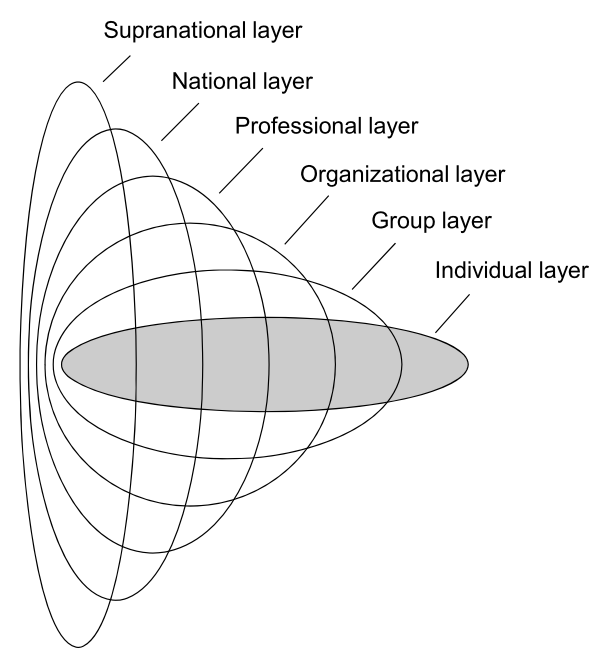

Virtual onion model by Karahanna et al. (2005) of Hofstede's approach (House and Javidan 2004). The results extend and substantiate Hofstede's cultural dimensions to finally nine dimensions (assertiveness, gender equality, group collectivism, humane orientation, institutional collectivism, performance orientation, power distance, uncertainty avoidance and future orientation). Further - contrary to Hofstede - the practices (as is state) and values (should be state) of each dimension are distinguished in order to achieve a separation between lived and desired cultural values in a nation.

Critics of the concept of national culture also exist. For instance, Myers and Tan (2002) note that nations are a phenomenon of recent history. Effective national governments equipped with appropriate power were already formed in the 19th Century (e.g., in Europe and the U.S.). It is thus problematic to equate nations with cultures, since they may have existed for several thousand years. Furthermore, national states vary continuously. Here, among others, the dissolutions of the Union of Soviet Socialist Republics (USSR) and Yugoslavia can be mentioned. The basic idea that every nation corresponds to a culture is incorrect. For example, India was founded without a common language and ethnicity, and consists of a large number of distinct cultures. In Africa, many nations were founded by the dominant colonial powers without taking cultural and ethnic lines into account (Myers and Tan 2002). Consequently, it seemed more realistic to assume that a nation would involve more than one culture or several subcultures (Huo and Randall 1991;
Peppas 2001; Martinsons and Ma 2009). The approaches described below choose a further reference object (organization or group), thus avoiding this criticism.

\subsubsection{Organizational Cultural Research}

In organizational cultural research the common values and behaviors of members of each organization are important. According to Hofstede et al. (2010), this is a fundamentally different cultural phenomenon compared to national culture, which is why these topics should be strictly separated. One of the most popular explanations of organizational culture is the model of Schein (2004). Following this approach, corporate culture can be divided into three levels (Fig. 1, left side). The visible artifacts are located at the top (e.g., language used, clothing, and technology). Below them are the not directly visible levels of values. Joint values reduce the uncertainty of the organization's members in making decisions in new situations and thus serve as a guide. At the lowest level are the so-called basic assumptions. Values that have been successful over a long period can evolve into basic assumptions. There is thus a substantial difference compared to the values in terms of the amount of anchoring within the organization. At the basic assumptions, the anchoring is so strong that a critical discussion is no longer possible, and if the members of the organization do not stick to the basic assumptions, they are excluded from the community organization (Schein 2004).

\subsubsection{Cultural Group research}

In addition to the national and organizational culture approaches, numerous publications over the last few years can be assigned to neither of these approaches (see e.g., Martinsons and $\mathrm{Ma}$ 2009; Sarker and Sarker 2009; Rai et al. 2009.): These works mainly deal with group cultures, which, for example, occur in communities. A theoretical explanation for such cultural forms, including the theory of social identification, is based on the self-concept (Tajfel 1972; Tajfel and Turner 1979). Following this approach, the inner self of an individual arises from group membership (nationality, profession, and organization) and the specific context. Instead of a rigid character, it is assumed that many personality facets exist in different situations that determine behavior (Tajfel 1972; Tajfel and Turner 1979). Karahanna et al. (2005) have developed the so-called "virtual onion model," based on the theory (Fig. 1, right side). The different group memberships assign themselves around the core of the individual personality just like the skin of an onion, thus forming the respective dominant culture. Since the number of the considered group membership is unlimited, the approach can be used to explore different group cultures very flexibly.

\subsection{Conception of the Regulatory Framework}

The framework relies on the model of the system design by Fettke et al. (2010), 
Fig. 2 Framework for the literature analysis (own illustration)

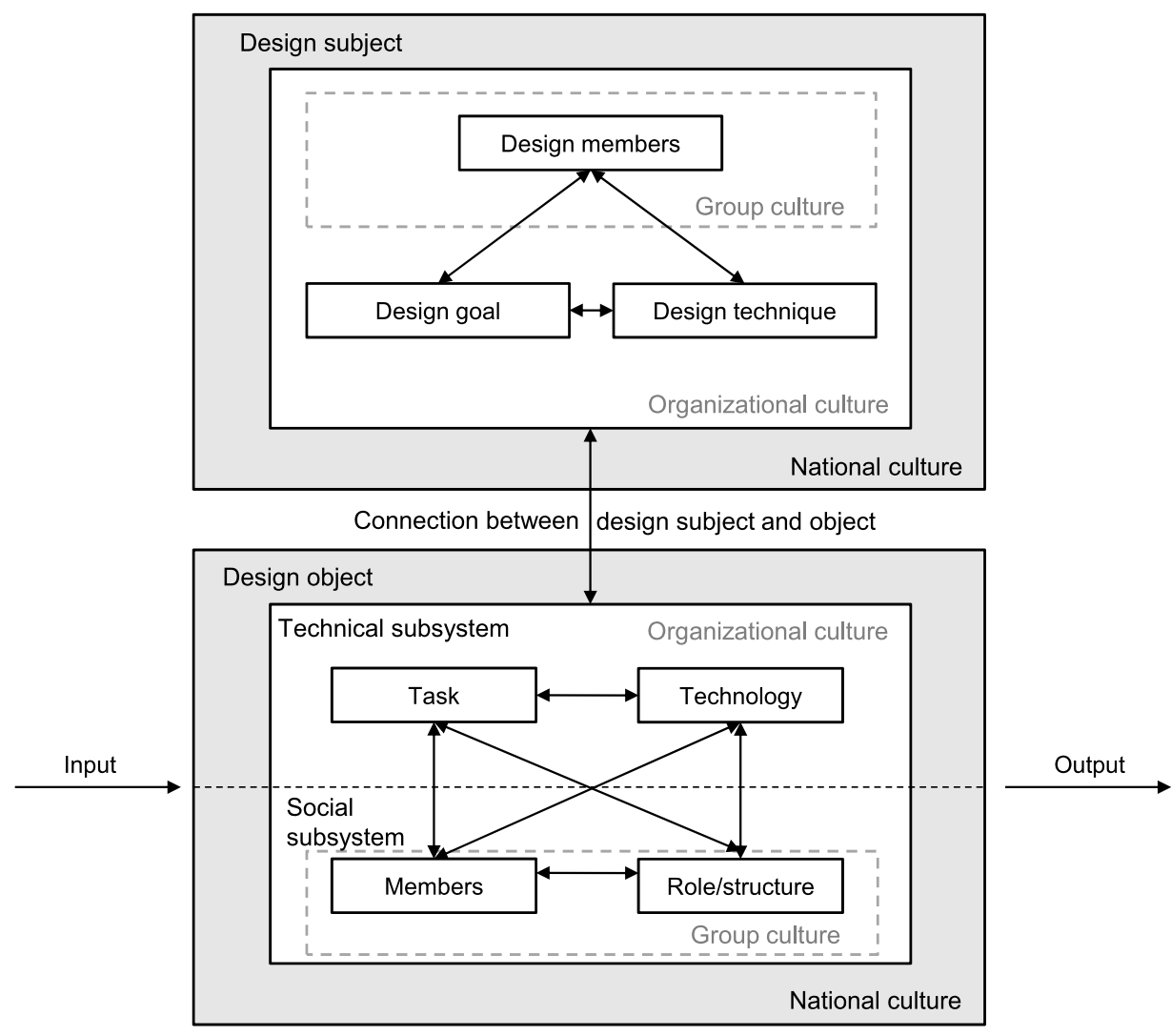

which is a synthesis of various corresponding approaches providing a comprehensive aggregated basis (Sect. 2.1). Thereby, we particularize the design object of the model referring to the distinction above - as a socio-technical system - at this layer with the approach of Sydow (1988, Fig. 2). Afterwards, we embed the single components/layers of this extended model in the corresponding type of culture (Sect. 2.2).

We follow the assumption that both design subject (e.g., the business analyst in a given country) and design object (e.g., the introduction of a business process management system in another country) are generally characterized by the respective national environments in which they are anchored (Sect. 2.2) so that the design of information systems is dominated by this type of culture.

With the embedding of organizational culture, we follow Schein (2004). Accordingly, culture comprises not only a visible range but also unapparent, not directly accessible components (Sect. 2.2). These are connected with the actors involved - design subject (e.g., business analyst) and design of object (such as key account manager) - and are perceived by them as a matter of course. Not directly accessible cultural components represent val- ues and basic assumptions, whose diversity is often associated with risks for the design of information systems. Different values can therefore result in other functionality requirements (Ishii 2004; Choi et al. 2005), which lead to reduced efficiency and effectiveness of the system if these requirements are not met.

The approach of the virtual onion model (Sect. 2.2) emphasizes - in our view - that national culture is only one of the many layers of culture, which, in turn, overlap with each other and are strongly connected. Thus, the national culture (e.g., French/German) influences the organizational culture (e.g., centralized/decentralized) or the group culture (e.g., specialized/revenue oriented). Accordingly, there remains to be considered the importance of further types of culture for the design of information systems in general in order to eventually develop a complete image in this area. Given the objective of this paper and the previously discussed focus on the national culture, organizational and group-specific aspects fade into the background. This is highlighted within the framework and Fig. 2, through adjustments of the font color (shaded).

The framework described here (Fig. 2) provides first general indications for the targeted - culturally specific - design of information systems, pointing out the appropriate interfaces and research potentials. It can also be used as a basis for answering the above-mentioned questions, as the papers identified in the literature review are assigned to the design subject, the design object or the connection between them. On the other hand, it is possible to focus on the type of culture in the foreground. In the following, we focus in particular on the national culture (Table 1). For further structuring of the single results, they can be assigned to the typical phases of the design of information systems. The practical application of the regulatory framework for structured analysis of existing research is discussed in the following section.

\section{Methodology}

The methodology employed to identify suitable papers is based on Buhl et al. (2011) and Piccoli and Ives (2005). The approach is based on a sample of published research papers in journals and conference proceedings (see details in online Appendix B). With the use of a systematical database search, we identified publications by keywords that dealt with 


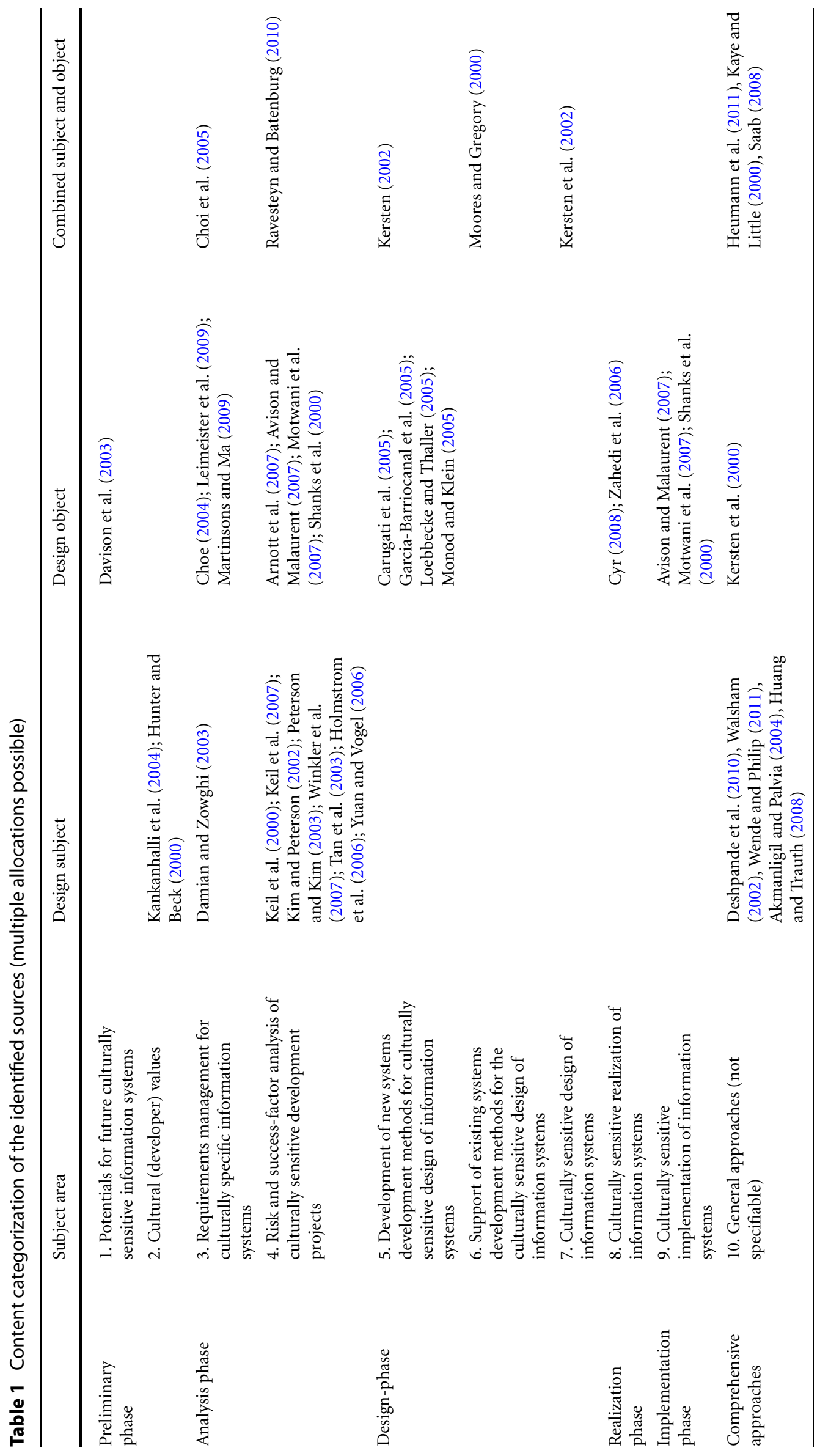


the topic of culture in information systems development, or were directly related to this topic. Only research articles were included that were published between January 2000 and July 2011. A detailed explanation of the selected databases, the search terms used, and the identified contributions to the multilevel consolidation are included in online Appendix B. A total of 39 papers from 12 journals and 7 conference proceedings were identified.

The structure and presentation of the results in terms of the concept of focus and discussion (language style and tenses) were based on Webster and Watson (2002). Initially, the papers were assigned to the layers of the system design's model regarding our framework (Fig. 2). The levels of the design subject, the design object and the connection between subject and object design were distinguished. Thereafter, the identified themes were condensed into priorities and were assigned to typical phases of system development (Sect. 2.1). Thereby, a distinction was made between pre-phase, analysis phase, design phase, implementation phase, and introductory phase, following Stahlknecht and Hasenkamp (2004). Additionally, a cross phase category was added. Unless substantive aspects allowed a further subdivision within a phase, the articles in several issues were divided (Table 1). Because, for example, the design phase required the selection and use of appropriate development method (Stahlknecht and Hasenkamp 2004), these phases could be divided into two subject areas: one for the development of (new) system development methods (Table 1 - subject area 5) and one for the support of (existing) system development methods (Table 1 - subject area 6). Afterwards, the identified papers were analyzed to what extent they were appropriate in order to answer the defined research questions (Sect. 1). Below, the results of the classification and analysis are explained.

\section{Culture in Design Science Research}

In the following, we present the results of the literature analysis for which we apply the framework given in Fig. 2, serving as a possible basis for a culturally sensitive development theory. The list of contributions is summarized in Table 1 , and is based on the individual phases or subject areas of the development of successful socio-technical systems, resulting in the various rows presented in the table. Where there is a sample for each field, they are explained in detail.

Thus, the first research question posed in Sect. 1 regarding the research results obtained in the different areas, is addressed. On this basis, extant research gaps for each topic are uncovered. We then focus on the second research question concerning which potential areas of research remain and how they can be exploited. A complete list of the analyzed contributions and their findings is provided in online Appendix A.

\subsection{Preliminary Phase}

The preliminary phase consisted of contributions which focused on research questions which preceded actual development. Specifically, these were the identification of culturally sensitive information systems for future research projects and had fundamentally different value systems among developers.

Subject Area 1 - Potential for Future Culturally Sensitive Information Systems:

This subject area focuses on the identification of culturally strong influenced information systems which directly lead to the initiation of future research projects. Cultural aspects are therefore examined before the system is developed conceptually or empirically. Davison et al. (2003) make the only contribution that could be allocated to this category. In this conceptual contribution, e-commerce opportunities are identified along the former Silk Road in Central Asia. Regarding the infrastructure of the Silk Road, a relatively well-developed mobile network is being established, which is why mobile devices play a key role. Nevertheless, there are barriers due to a lack of payment systems, resulting in credit cards rarely being accepted in Western China. There are also cultural issues that arise from the large number of participating countries (Turkey, Kazakhstan, Turkmenistan, India, Nepal and China). The regions involved are also relatively poor, thus leading to economic problems. The authors therefore believe that the development of a functioning e-Silk Road will take several years. It should furthermore be noted that this contribution is relatively general and offers no theoretical basis for its claims.
Since only one contribution can be allocated to this subject area, only very general research questions can be derived:

- Which other areas have a high potential for culturally sensitive information systems?

- How can these potentials be exploited?

Subject Area 2 - Cultural (Developer) Values:

This subject area is also upstream of actual development and includes the general (national) cultural influences on developers and their inclusion, through team-building, in development projects. The two identified contributions each use Hofstede's cultural dimensions as a theoretical starting point. First, Kankanhalli et al. (2004) investigate the interdependence of values of individualism and collectivism and masculinity and femininity, following Kumar and BjornAndersen (1990). The authors manage to demonstrate the influence of both cultural dimensions on the technical, economic and socio-political values of the developer on the basis of empirical data from the USA and Singapore. Individualism and masculinity are correlated positively with both economic and technical values, while there is a negative correlation with socio-political values. These results should be considered during the composition and management of crosscultural teams. In the second contribution, Hunter and Beck (2000) also examine cultural developer values at the level of subject design. Using the repertory grid technique (Kelly 1955, 1963), the authors show that different cultures have different standards, and different quality criteria for performance assessment are used. This qualitative study assessed different constructs through interviews, and the selection of the examples - Canada and Singapore - was based on Hofstede's cultural dimensions. Among other things, a more technocratic approach of system analysts in Singapore was identified, in which expertise plays a dominant role in an IS project. In contrast, Canadian system analysts take more of an advisory role and try to involve customers in a more collaborative process. These roles differ according to different expectations of the service to be provided. The focus of the article, however, is more on the development of a methodology and less on a dedicated performance analysis.

Against this background, the following research questions seem significant in this field: 
- What are the effects of different cultural (developer) values on the design object?

- Can the results be generalized to other countries with similar characteristics in terms of their cultural dimensions (e.g., to China, with respect to collectivism)?

\subsection{Analysis Phase}

Following Stahlknecht and Hasenkamp (2004), the analysis phase is divided not only into an as-is analysis, where the existing system is examined, but also a target analysis, where an initial target concept is developed. This category can be organized into two subject areas: requirements management, as well as the detection and consideration of risk and success factors analysis.

Subject Area 3 - Requirements Management for Culturally Specific Information Systems:

This subject area includes the contributions which focus on culturally specific information on the collection or mapping of culturally specific requirements. The identified contributions cover design subject and object and their relations to one another. Damian and Zowghi (2003) come to the conclusion that requirements management among global software developers in Australia and the USA is affected by conflicts based on cultural differences.

Choe (2004) points to cultural differences in functionality requirements for information systems in accounting which should be considered in the design of such systems. Korean companies put more emphasis on flexibility, while Australian firms, in particular, value output quality and traditional information on cost control.

Leimeister et al. (2009) also demonstrate that the requirements of CIOs in RFID are associated with different strategic goals. While German CIOs focus on, quality improvement, the reduction or automization of manual tasks, reduction of faulty products and an improvement of customer service, the aims of Italian CIOs are primarily directed towards the reduction of inconsistent product lines, optimization of inventories and the improvement of customer service. Drivers of these strategic goals can be determined by factors such as experience with RFID, company size and the perceived potential of the technology. Hofstede's cultural dimensions are used to explain the difference between German and Italian firms with respect to these factors. For example, following Hofstede, the lower level of experience with RFID in Italy leads back to the higher degree of uncertainty avoidance.

Choi et al. (2005) identify 52 attributes that exert an influence on the use of mobile data services. In addition, eleven critical attributes are identified which have a direct link to the user's culture. The paper uses the theoretical foundations as well as the cultural dimensions of Hofstede (uncertainty avoidance and individualism/collectivism). In addition, Hall and Hall (1990) use the cultural dimensions of context and the perception of time. As an example, the context in Korea and Japan favors more content and more symbols in the overview design, taking into account the variance in font colors and font sizes. In Finland, on the other hand, less content and fewer icons in the overview design and a smaller variance in font colors are favored. These differences in requirements should be used in the design of mobile data services in different cultures in order to achieve a higher rate of acceptance. Regarding substantive classification, Choi et al. (2005) focus mainly on subject design. Since actual potential users were surveyed, however, the contribution represents a combination of both aspects.

Martinsons and Ma (2009) analyze the extent to which different Chinese subcultures differ regarding the ethics of information managers. Here, instead of the usual cultural dimensions of Hofstede, the authors use dimensions belonging to the generational sub-culture theory of Strauss and Howe (1991) and lifecycle theory of Erikson (1997). These approaches do not assume a homogeneous culture, but explain age-related differences in a nation's culture, where selfinterest, social relationships, laws and rules, majority rights, and equality and fairness can be used as indicators of moral differences. The results suggest very westernized, traditional, and modern Chinese cultures that necessitate appropriate adjustments with respect to requirements management. This work also raises doubts about the cultural conceptions of Hofstede and the GLOBE study (Sect. 2), which stem from just "one" Chinese culture.
In summary, it can be said that culture entails different requirements for information systems that should be considered in development. Moreover, requirements management itself is also influenced by culture and is therefore implemented differently in different cultures. In this context, the question arises as to whether these results can be generalized to the entire national culture or whether, following the assumptions of Martinsons and $\mathrm{Ma}$ (2009), sub-cultures exist within a single nation, and thus the requirements can vary significantly. Considering not only the size and diversity of some countries, such as China and India, but also the differences between generations as well as between rural and urban population, using Hofstede's classification for an entire nation is likely to be, at best, inexact.

Based on these examples, the following research questions seem relevant:

- To what extent do national subcultures exist and how different are they when compared to Hofstede's dimensions?

- Can the identified differences regarding requirements actually be traced back to the explanation of the cultural dimensions used?

Subject Area 4 - Risk and Success Factor Analysis of Culturally Sensitive Development Projects:

To this subject area contributions have been assigned that deal with the analysis of critical factors for development projects. The analysis of risk factors is usually done as an accompanying or cyclical part of the development process (Boehm 1986). Where possible, the contributions are therefore also associated with a specific phase of the development process. Cultural factors which are relevant to the success of information and communication technology (ICT) development projects can be identified at all cultural levels. Because of the numerous contributions presented under this topic, a detailed explanation is appropriate. With regard to the object of study, the design subject - specifically the design team (Fig. 2) - dominates the orientation of the contributions in this field. The focus of research is on the collaborative development of information systems in different national cultures. A commonly identified phenomenon in the Asian region is the avoidance of the loss of face and associated communication problems (Winkler et al. 2007; Keil et al. 2007; 
Tan et al. 2003; Yuan and Vogel 2006). This can especially lead to problems in offshore projects where designers from different countries work together. Peterson and Kim (2003) have studied the cultural differences that exist in the perception of success factors for software developers from the USA, Korea, and Japan. Insufficient user involvement and inadequate experience are perceived as being problematic in Korea. In addition, project goal definitions and missed deadlines are presented as a major issue in Korea that leads to development failures. In contrast, the developers in Japan and the USA report similar results, where the success factors are judged more positively. Likewise, Keil et al. (2000) have found that the failure of software development projects in different cultures is judged differently. In concrete terms, Finland, the Netherlands, and Singapore are compared in terms of how they deal with sunk costs and the risk behavior of decisionmakers. While the level of sunk costs motivated stakeholders in all cultures to take on more risk, it could be shown that the tendency to take risks in countries with a low degree of uncertainty avoidance, such as Singapore, meant that the perception of risk was reduced and critical projects were continued for longer.

In addition, the contributions of Avison and Malaurent (2007), Motwani et al. (2007) and Shanks et al. (2000) are assigned to this subject area. They analyze critical success factors for the implementation of Enterprise Resource Planning (ERP) systems. Due to the thematic focus of this section, these are considered in Sect. 4.5 (implementation phase) in more detail. The article by Ravesteyn and Batenburg (2010) examines the relationship between the designer on the design subject side and actors on the design object side. Cultural differences in the implementation of business process management systems that are influenced by these two levels are examined. Instead of using general cultural dimensions, volunteers from northern Europe and the Anglo-American countries were asked questions which concerned their understanding of the concept of business process management, management support and expertise in change management. It becomes clear that the critical success factors for implementing business process management systems can be classified into five culturally independent areas (management, organization and processes, measurement and control, implementation and change management, architecture, and solution development). However, the importance of individual factors differs significantly in these areas. Thus, the intelligibility of the overall concept, the processes and their relationship to each other, as well as a high level of support from management are considered important, particularly in northern Europe.

Furthermore, contributions are identified that address the design subject and thereby connect aspects of national and organizational culture. Tan et al. (2003) come to the conclusion that the decision over whether or not bad news is communicated to a software project is - in countries with a high degree of collectivism - primarily influenced by the organizational climate. In contrast, Holmstrom et al. (2006) conclude that differences in socio-cultural distance affect global development projects. Socio-cultural distance, following Ågerfalk et al. (2005), refers to the coming together of aspects of national and organizational culture, indicating the extent to which an actor understands the values and normative actions of others. Further, the effect of temporal and geographical distance was investigated (Ågerfalk et al. 2005). As a result of a case study, particular communication difficulties are described, which include, for example, the use of different languages and terminology, as well as differences in the assessment of the time required. However, although the same problems occurred in all of the four companies studied, different strategies were pursued. On a theoretical level, due to the combination of different attitudes (national and organizational) to distance, greater explanatory power is gained over traditional explanations, such as those of Hofstede.

Numerous contributions concerning success factors have marked similarities: loss of face in Asian countries, communication and coordination problems, power distance, uncertainty avoidance and collectivism. Cultural dimensions are thereby often used as a justification of observed phenomena. Discrepancies between the results could not be identified; however, the importance of individual factors was valued differently across contributions.

Analysis of the contributions in this field led to the following research questions:
- To what extent can the concept of socio-cultural distance be applied to other subject areas?

- Why do expressions of the observed phenomena, such as "understanding of the overall concept and the processes" or "lack of experience," vary in different cultures?

\subsection{Design Phase}

In the design phase, the information system based on the previously determined target requirements is developed (Stahlknecht and Hasenkamp 2004). A system design is created using system development methods. This phase could be assigned to contributions that deal with the development and support of culturally sensitive systems development methods, as well as contributions that address culturally sensitive system design directly.

Subject Area 5 - Development of New System Development Methods for Culturally Sensitive Design of Information Systems: In contributions assigned to this subject area, new systems development methods and architectures are introduced that take culture into account explicitly. Numerous articles are identified. All of them consider as the main task of the design object to address the storage of culture in terms of cultural heritage through information systems (Carugati et al. 2005; Garcia-Barriocanal et al. 2005; Loebbecke and Thaller 2005; Monod and Klein 2005). These contributions are predominantly design science oriented and include methods and architectures for developing such systems. Thus, Loebbecke and Thaller (2005) imagine a reference architecture that supports the digitization of cultural objects (such as the inventory of a museum) which is made available online. They support their argument with two case studies. These contributions address a cultural task with a specific technology, so they can be assigned to the elements task and technology in our framework (Fig. 2). The focus on these two elements clearly shows, however, that the social subsystem has not been addressed and therefore provides opportunities for future research. No studies were identified that examine how cultural preferences influence, e.g., the digitization of cultural heritage.

Another contribution (Kersten 2002) describes a new methodology for assigning information systems according 
to the culture of users, hence producing a connection between design object and subject. Based on the development of e-business systems it reveals that by considering cultural artifacts you need more than a revised design of the interface (e.g., linguistic adaptations). Instead, Kersten (2002) emphasizes that the core application would also have to be adjusted in accordance with cultural preferences. Aspects such as system openness, flexibility, stability and ease of use are examples of properties that are associated with cultural values and can be articulated in, among others, the choice of Windows or Linux-based operating systems. Where various forms of culture (national, organizational) are mixed, the author explains, using examples to show how the development of different levels of e-business systems, including the core software, can be adjusted to a culture. In addition, new development paradigms are proposed, such as aspect- or subjectoriented programming, to realize cultural properties during application development.

The results are the following research questions:

- Which national cultural differences do systems provide that store cultural heritage?

- Can the conceptual requirements of Kersten (2002) related to the adjustment of the core application be confirmed empirically?

Subject Area 6 - Support of Existing System Development Methods for a Culturally Sensitive Design of Information Systems: This category includes contributions that focused on existing methods to support cultural factors in the development of information systems, that is, to address cultural aspects of the socio-technical system in a manner which is methodologically adequate. Moores and Gregory (2000) study culture related problems with the use of Soft Systems Methodology (SSM). SSM is an analysis and design methodology that makes it possible to structure problem situations, taking into account human actors and their cultures (Checkland 1981). The example of China (in this case, Hong Kong) shows three cultural problem areas in software development: group discussions are avoided, interviews are conducted in several languages, resulting in communication problems, and due to a high staff turnover in management, difficulties arise in the consistent consideration of stakeholder-interests.
The following research questions are identified:

- How can design methods account for various sub-cultures in the development of the system?

- Which development methods are suitable for which cultures?

- According to which cultural factors should a particular method be chosen?

Subject Area 7 - Culturally Sensitive Design of Information Systems:

Kersten et al. (2002) examine the influence of culture on the surface and core application design. The contribution is closely linked to Kersten (2002) (see subject area 5). They reveal that within the software design process culture is often reduced to language and symbols or in other words the instrumental theory of technology is applied. This approach is aimed at international software developers whose interfaces are adapted for national markets. This contrasts with a holistic understanding of culture and the so-called material or critical theory of technology. Since software applications are tailored towards user interaction, under this broad cultural understanding, it is not sufficient to adapt the user interface only to existing cultures. Rather, an adjustment of the core software should be the goal. Kersten et al. (2002) provide the example of a decision support system in France. According to Hofstede's dimensions a high degree of power distance and a feminine orientation exist, therefore quality of life, relationships, and authority are of high value. For this reason, the system should take into account the authority of the decision-maker, and also offer considerable freedom, which should also be taken into account in the system design. Kersten et al. (2002) propose an approach in which there is a distinction between the culture-dependent and culture-independent components, which must then be adjusted according to a modular design approach. The theoretical link between cultural and technological understanding remains unsolved in the identified contributions and is an appropriate starting point for future research projects. Since, alongside the user, specific design techniques are considered, this contribution has been assigned to two subject areas.

The following research questions seem particularly important:

- To what extent can the theoretical concept developed by Kersten et al. (2002) be used in practice and are the resulting systems actually purposeful?
- How far does the cultural background of the designer influence the system design?

\subsection{Realization Phase}

Contributions which deal with the realization of previously specified systems were assigned to this phase.

Subject Area 8 - Culturally Sensitive Realization of Information Systems:

For realization, only contributions which deal with the design of web pages are identified. These build upon usability literature and consider Hofstede's cultural dimensions. For the example of online shopping, Cyr (2008) investigates the extent to which information design, navigation design and visual design affect trust and satisfaction. Both of these factors influence so-called e-loyalty, defined as the intention to return to a web page or to consider it in future purchasing decisions. E-loyalty therefore represents a key characteristic of customer loyalty. The results show that trust is particularly important to e-loyalty in countries with a high degree of uncertainty avoidance. For this reason, this factor is more relevant in Germany and China than it is in Canada. Furthermore, building on the existing literature, a large degree of collectivism in China can be associated with contrasting colors and visual effects, while in Germany, a logical and highly structured layout is preferred, due to the high degree of individualism (Sun 2001). The results support this hypothesis, since a relation between visual design and trust could be only established in China. Overall, the various designs seem appropriate to explain trust and satisfaction cross-culturally, and also to account for e-loyalty indirectly.

In contrast, Zahedi et al. (2006) study the influential relationship between culture and Hofstede's cultural dimension of masculinity-femininity to improve the efficiency of web documents. Cultural content should be adapted to the values of the target audience; otherwise, culturally confusing messages could arise and distort communication. Web documents with a masculine influence are characterized by the dense presentation of facts, and use words which are typically associated with manly attributes. On the other hand, more feminine web documents are characterized by factors connected with charity, community, sharing and interpersonal relationships. Zahedi et al. (2006) identify these stereotypical 
attributes in various websites, and show that several sites use a design which is unsuitable for the target group. Although this deals with a typically national cultural dimension, no connection is made to this field of research. It remains unclear, therefore, whether the results can be generally applied to both masculine or feminine influenced nations. For the classification of contents, both approaches address object design, and humanity in particular.

From these contributions, we can derive the following research questions:

- To what extent do the cultural backgrounds of designers (e.g., regarding design preferences) influence the realization phase?

- Can you transfer the results of Zahedi et al. (2006) to male or female influenced countries?

- What are the consequences of not considering cultural differences in the process of realizing core applications?

\subsection{Implementation Phase}

This phase involves the actual implementation of a pre-specified system. Consequently, the contributions assigned to this phase deal with cultural challenges in implementation.

Subject Area 9 - Culturally Sensitive Implementation of Information Systems: At the level of the design object Avison and Malaurent (2007) identify culturally related problems in China, resulting in a case study described as a failure of an Enterprise Resource Planning (ERP) implementation for a French company. The problems identified include the language and communication behavior of users (e.g., through loss of face or problems with understanding instructions in English), economics (unexpected local reporting requirements) and structural factors (respect for the corporate hierarchy). The authors therefore conclude that the use of global templates to support system implementations can have negative consequences.

Motwani et al. (2007) thematize the relationship between humans and a specific technology at the level of the design object. Cultural differences arose in the implementation of ERP systems between India and the United States, particularly relating to Hofstede's dimensions of power distance and individualism/collectivism. Power distance in India means that the top management there acts much more unilaterally, setting milestones and monitoring compliance. In contrast, in the US, due to the lower power distance, there is more of a team approach, with collaboration in the major decisions. In addition, external experts are accepted more readily in collectivist societies such as in India, while the more individualistic culture of the US has more confidence in the technical expertise of their internal employees.

There are, however, also factors for success in professional project management that work across cultures. Shanks et al. (2000) conclude that in the introduction of ERP systems the social subsystem is mainly influenced by the cultural dimensions of power distance and individualism/collectivism. This is based on case studies from China and Australia, since in countries such as China with a high degree of power distance and collectivism, fewer resources must be used to convince people to change their behavior.

As all of the contributions in this subject area study risk factors, they were also assigned to subject area 4.

For this subject area, the following questions seem particularly relevant:

- To what extent does the cultural background of the designer influence the implementation phase (e.g., regarding design preferences)?

- Can global templates for system implementation differentiate culturedependent and culture-independent components?

- Can the recurring observations about cultural dimensions of power distance and individualism/collectivism be generalized?

\subsection{Comprehensive Approaches}

Subject Area 10-General Approaches (Not Specifiable):

There are several contributions which could not be assigned to any of the previous subject areas (online Appendix A, Table 1). These are comparatively broad approaches that deal with the entire development process. At the national level, for example, Deshpande et al. (2010) show techniques for dealing with cultural differences in global software development, and illustrate, using the example of India, how these differences can be used as an advantage. India has a wide variety of sub-cultures, with more than 850 languages and over 1,600 dialects spoken, in conjunction with a variety of religions and local customs, evidence of considerable diversity, and thus project managers have to develop strategies to deal with this diversity. An example is the provision of a back-up team to the field to address staffing problems due to various holidays, thus providing 24-hour support, 365 days a year. Likewise, all team members are made aware of cultural differences. There is special training in which Hofstede's cultural dimensions, among others, are discussed, improving both the cooperation within the team as well as relations with the client.

In contrast, Heumann et al. (2011) aim with their article on the connection between design object and design subject to examine the interaction between the culture of designers and the client's choice of control mechanisms in IS off-shoring projects. They combine theoretical concepts from culture research with control theory. A special feature of this is that the authors use a questionnaire to gather and evaluate information at the individual level concerning the selected cultural dimensions of power distance, individualism/collectivism, uncertainty avoidance and activity/passivity, after Triandis (1982), and mono/polychronic time perception, after Hall and Hall (1990). The findings indicate that power distance influences informal control, resulting in two reciprocal effects. While a high degree of power distance relies on social control mechanisms such as rituals and ceremonies, to reduce differences between objectives, in a lower power distance situation more self-control is required. This seems plausible, since these control mechanisms require a greater degree of autonomy that is not provided by cultures with a high degree of power distance due to the clear structures and expectations of supervisors. Nevertheless, the influence of the national culture of suppliers is overall relatively low.

For this subject area, the following research questions are identified:

- Can the results of Deshpande et al. (2010) concerning the use of cultural differences be transferred to other cultural areas with less diversification?

- Can the often cited explanation of cultural differences dimensions provided by Hofstede also be used empirically to demonstrate causal factors (as in Heumann et al. 2011)?

- Can further cultural differences in the system design be derived from the construct of the activity/passivity, following Triandis (1982)? 


\section{Implications}

In this section, we address research questions 1 and 2 formulated in Sect. 1 and summarize the previous results (Sect. 5.1). Then, in line with the third research question, we consider the relationship between theories of culture used in the literature and theories related to the design and development of information and communication systems (Sect. 5.2).

\subsection{Summary of Results}

The results can be summarized into two main areas: (a) Concerning design subject, how should cross-cultural development teams be managed? (b) Regarding the dominant force in shaping design objects, how should information systems be designed as socio-technological systems in different cultures? Our framework (Fig. 2, Table 1) builds on the current state of research for both questions and illustrates different research potentials. Regarding a), there are various results, which often describe only individual phenomena. Consequently a comprehensive synthesis and analysis of the various findings mainly regarding external validity are commendable. In contrast, regarding (b), further research is necessary. The existing approaches focus only on the identification of culturerelated variability. Methods for the development and evaluation of appropriate culturally sensitive information systems are still lacking.

Among the investigated contributions, a homogeneous understanding of culture at the national level, in the sense of Hofstede (1980) prevails. However, this can be drawn into question, especially in diverse and rapidly developing countries such as China and India, which now have a variety of value systems in place (Martinsons and Ma 2009). The use of uniform cultural dimension values is thus problematic. This gives rise to groupspecific cultural approaches which can also explain the different national cultures and sub-cultures within a country (Sect. 2.1). In this context, it should be examined to what extent divergent results - for individual questions previously considered to be aspects of national cultures - can be explained through group and sub-cultures. In marketing especially, researchers use so-called "ethnic" approaches at the group level for potentially culturally sensitive solutions. Issues of ethno-marketing arise with end consumer products, such as the marketing of particular brands and mobile phone rates to people with immigration backgrounds in Germany and Hispanic immigrants in the USA. In parallel, the design of information systems could be targeted to specific group and sub-cultures through different cultural considerations.

In terms of the examined timescale, it is clear that there are often conflicts in projects (Kaye and Little 2000; Damian and Zowghi 2003; Winkler et al. 2007). Longitudinal research results, which are connected to various points in time, could not be identified, which could be connected to a static understanding of culture. Cultural change over time and the corresponding opportunities for control should continually be assessed and considered in the design of information systems. Corresponding dynamic approaches and associated culturally sensitive regulations have yet to be explored.

The development process of information systems is usually, in the context of culture, studied in a general manner. Work on specific phases of the development process (Sect. 4) is occasionally distributed. Thus, work on "classical" phases of system development such as system design (Table 1 - Subject area 7) or implementation (Table $\mathbf{1}$ - Subject area 9) is difficult to classify. For other phases, such as verification and validation (Boehm 1986), no contributions could be identified. Abstract general statements can help, but have a limited usefulness in concrete development projects. For this reason, future research using appropriate theoretical approaches should examine specific activities in order to support practical projects.

The interaction of different types of culture is another research area that is still largely unexplored. It would thus be conceivable that in internationally engaged development teams, the national or organizational culture of the group would be sidelined, thereby reducing known cultural problems. In this context, it should be investigated which cultures dominate when, and how this might be influenced. Therefore, an analysis of specific causeeffect relationships becomes necessary in order to obtain recommendations for action as well as control instruments.

The contributions which deal with design subject and design object are mostly of a general nature and cannot be directly allocated to a specific subject area. The context of design subject culture and design object culture could provide a deeper insight into typical conflicts. A possible area would be cultural conflicts caused by the external system design and system implementation. In addition, the question arises in connection with the development of products for the end user as to how future cultural differences in use can be taken into account during development in order to allow for culturally sensitive designs.

\subsection{Towards a "Theory of Culturally Sensitive IS Design"?}

The third research question refers to the theories in general, and asks which theoretical models of culture are used specifically in the design of information systems. On the basis of the selected articles, this issue has been addressed in Sect. 4 . In the following, these results are further condensed:

During the literature analysis, articles were identified that have no theoretical frame of reference for culture. These are paper which mainly use no empirical data, including contributions that relate to the storage of culture - cultural heritage - my means of information systems (Carugati et al. 2005; Garcia-Barriocanal et al. 2005; Loebbecke and Thaller 2005; Monod and Klein 2005). The authors focus on the design perspective and consider culture exclusively as a task. Davison et al. (2003) can also be assigned to this group, since their comments on the e-commerce potentials along the former Silk Road have no theoretical reference. The reasoning behind these articles is based mostly on the obvious nature of cultural differences.

Further, contributions are identified which reveal no theoretical foundation and only aim to identify differences. Peterson and Kim (2003), for example, refer to the fact that contributions to software risk management come primarily from western countries, and therefore compare the perception of risk factors across Japan, Korea, and the U.S. There are also works which, in explaining previously identified differences, use only theoretical constructs from the literature. Thus, Akmanligil and Palvia (2004) cite Hofstede to explain the differences in outsourcing behavior.

A number of the identified contributions follow a unified theoretical framework to connect culture and the design of information systems. The dominance 


\section{Abstract}

Tyge-F. Kummer, Jan Marco Leimeister, Markus Bick

\section{On the Importance of National Culture for the Design of Information Systems}

In this contribution a literature review is conducted to illustrate how national culture influences phases of the design of information systems. For this purpose, we review the literature in order to identify reliable and commonly approved findings as well as still open remaining questions. Fundamentally, our literature review is a comprehensive framework that sets typical dimensions of system design as well as main types of cultural research in relation to each other. The existing research results in the area of national culture are classified along the levels of system design and attributed to typical phases of the design of information systems. It thus becomes apparent that in the domain of culture and information system design it is often only the design subject or the design object that is addressed. Contributions that connect both levels rarely exist. In our review, only a limited number of publications could be identified that covered concrete phases of the development providing system design, implementation, as well as verification and validation. From a theoretical perspective, there is an obvious dominance of Hofstede's cultural dimensions that well address single topics of the design, such as user interface and inter cultural problems in development teams. Other domains, however (e.g., technology and architecture), are inadequately explained. Further, a predominantly phenomenological focus becomes obvious. The observed cultural phenomena and the connected interpretations are usable in a limited way for concrete development initiatives. The contribution ends with the vision of a theory for the culturally sensitive design of socio-technical information systems that absorbs current scientific knowledge and unites it in a structured approach.

Keywords: National culture, System design, Socio-technical system design, Literature review of Hofstede's dimensions (Sect. 2.1) is exceptional in this context. These often represent the theoretical starting point and are also used to interpret the results (e.g., Shanks et al. 2000; Keil et al. 2000; Leimeister et al. 2009). Alternative constructs, such as those found in Hall and Hall (1990), are isolated (Choi et al. 2005; Heumann et al. 2011). Other conceptualizations are not evident in the considered sample. This is surprising, since, after the GLOBE study, alternative cultural dimensions exist which are based on a broadening of Hofstede's approach, given the distinction between values and practices, as well as the addition of more dimensions.

The connection of cultural models and IS design approaches is mostly rhetorical. An IS concept is first and foremost brought into a connection with cultural models. Motwani et al. (2007), for example, first introduce success factors for ERP implementations, and then point to possible connections with Hofstede's cultural dimensions. They then describe two case studies in which this relationship is concretized by means of empirical data. What is critical is the widespread habit of using the cultural dimensions to explain phenomena without testing the causal relationship between culture and the IS concept. Approaches which attempt to effectively merge IS concepts with models of culture are rare. Only Heumann et al. (2011) assess the cultural dimensions in a questionnaire and test a model which integrates both IS and culture.

Obviously, many of the contributions are not theory based and have little theoretical benefit for the culturally sensitive design of IS, since they work phenomenologically or relate to corresponding phenomenological groundwork. In addition, as a result of the dominance of Hofstede's dimensions, it is almost inevitable that certain subject areas can be well addressed (e.g., user interface, crosscultural issues in development teams, etc.), while other areas (e.g., technology and architecture issues) are insufficiently explained. The results of prior work for a comprehensive, integrated approach to culturally sensitive IS design are correspondingly limited. This dilemma is especially evident in the contributions of Kersten (2002) and Kersten et al. (2000, 2002), which do not specifically illustrate how a theoretical link between adaptation of core applications and national culture might be established. Moreover, from a theoretical point of view, as has already been shown in Sect. 5.1, a relatively simple understanding of national culture dominates that is static and assuming homogeneity within a country. More complex approaches which account for dynamics and sub-cultures, aside from Walsham (2002), have not been found.

\section{Conclusion}

This paper outlined the relationship between national culture and the various reference points of the design of information and communication systems. In terms of limitations, it should be noted that we reviewed a sample of contributions from the fields of business and information systems engineering and information systems by means of a literature review. Through the systematic collection of articles, we attempted to create a complete and comprehensive picture of the research in this area. It should nevertheless be assumed that in related disciplines, like management research or general intercultural comparison research, there are additional contributions which could have further enriched our paper. Furthermore, as a result of the focus on national culture, there are some far-reaching restrictions, as discussed in Sect. 2. Although considerations of subcultures beyond the level of national culture were found, the investigation was limited to the level of national culture. An extension of the analysis to further disciplines and forms of culture is therefore recommended.

In the context of the analysis, a variety of causal relationships emerged which were categorized by way of an ordering framework. A comprehensive review of the existing research landscape was made and subdivided into ten subject areas (Table 1-A, online Appendix A). It became clear in this categorization that the levels of design subject and design object should largely be considered separately in research.

The effect of cultural influences on these two levels is of great relevance, since cultural differences between both levels affect the development of sociotechnological systems. In this context, national cultures and their effects can be used to make the system design more responsive to design object. In addition, there is a general lack of design theories regarding culturally sensitive, sociotechnological development of informa- 
tion systems. The overwhelming majority of contributions identified in the literature analysis consider parallel phenomena from different perspectives. A thorough theoretical foundation would offer considerable advantages to research and practice. Scientists and researchers would have a basis on which they could systematize their research and falsify their theories, generalizing or broadening their concepts, while practitioners could transfer the identified causal mechanisms to specific development projects. This is due to the single phenomena identified and the sometimes highly speculative interpretations - at least for the moment quite limited. The proposed framework, taking into consideration the various cultural forms, provides a first step in the development of this approach with the elements of system development.

\section{Acknowledgement}

The authors are grateful to the anonymous reviewers and Professor Armin Heinzl for the constructive comments that led to a continuous improvement of the article.

\section{References}

Ågerfalk PJ, Fitzgerald B, Holmström $\mathrm{H}$, Lings B, Lundell B, Ó Conshúir E (2005) A framework for considering opportunities and threats in distributed software development. In: Proc of the international workshop on distributed software development (DiSD 2005), Austrian Computer society, pp 47-61

Akmanligil M, Palvia PC (2004) Strategies for global information systems development. Inf Manage 42(1):45-59

Arnott D, Jirachiefpattana W, O'Donnell $P$ (2007) Executive information systems development in an emerging economy. Decis Support Syst 42(4):2078-2084

Avison D, Malaurent J (2007) Impact of cultural differences: a case study of ERP introduction in China. Int J Inf Manag 27(4):368374

Becker J (1995) Strukturanalogien in Informationsmodellen - Ihre Definition, ihr Nutzen und ihr Einfluß auf die Bildung der Grundsätze ordnungsmäßiger Modellierung (GoM). In: König W (ed) Strukturanalogien in Informationsmodellen - Ihre Definition, ihr Nutzen und ihr Einfluß auf die Bildung der Grundsätze ordnungsmäBiger Modellierung (GoM). Physica, Heidelberg, pp 133-150

Boehm B (1986) A spiral model of software development and enhancement. Softw Eng Notes 11(4):22-41

Buhl HU, Röglinger $M$, Stöckl $S$, Braunwarth KS (2011) Wertorientierung im Prozessmanagement - Forschungslücke und Beitrag zu betriebswirtschaftlich fundierten Prozessmanagement-Entscheidungen. WIRTSCHAFTSINFORMATIK 53(3):159-169
Carugati A, Hadzilias E, Demoulin N (2005) Setting the framework for developing eGovernment services on cultural heritage. In: 13th proc European conf on information systems, Regensburg

Checkland PB (1981) Systems thinking, systems practice. Wiley, Chichester

Choe J (2004) The consideration of cultural differences in the design of information systems. Inf Manag 41(5):669-684

Choi B, Lee I, Kim J, Jeon Y (2005) A qualitative cross-national study of cultural influences on mobile data service design. In: Proc ACM conf on in human factors computing systems, Portland

Cyr D (2008) Modeling web site design across cultures: relationships to trust, satisfaction, and e-loyalty. J Manag Inf Syst 24(4):47-72

Damian DE, Zowghi D (2003) An insight into the interplay between culture, conflict and distance in globally distributed requirements negotiations. In: 26th proc Hawaii int conf syst sci, Hawaii

Davison R, Vogel D, Harris R, Gricar J, Sorrentino $M$ (2003) Electronic commerce on the new silk road: a conucopia of research opportunities. In: 11th proc European conf on information systems, Naples

Deshpande S, Richardson I, Casey V, Beecham $S$ (2010) Culture in global software development - a weakness or strength? In 5th proc IEEE int conf on global software engineering, Princeton

Erez M, Earley PC (1993) Culture, self-identity, and work. Oxford University Press, New York

Erikson EH (1997) The life cycle completed. Norton, New York

Fettke P, Houy C, Loos P (2010) Zur Bedeutung von Gestaltungswissen für die gestaltungsorientierte Wirtschaftsinformatik. WIRTSCHAFTSINFORMATIK 52(6):339-352

Gallivan M, Srite M (2005) Information technology and culture: identifying fragmentary and holistic perspectives of culture. Inf Organ 15(4):295-338

Garcia-Barriocanal E, Sicilia MA, Palomar D (2005) A graphical humor ontology for contemporary cultural heritage access. In: 13th proc European conf on information systems, Regensburg

Hall ET, Hall MR (1990) Understanding cultural differences. Intercultural Press, Yarmouth

Hampden-Turner C, Trompenaars F (1993) The seven cultures of capitalism. Doubleday, New York

Heinrich LJ, Heinzl A, Riedl R (2011) Wirtschaftsinformatik - Einführung und Grundlegung, 4th edn. Oldenbourg, München

Heumann J, Wiener M, Remus U (2011) The impact of national culture on control in IS offshoring projects. In: Tagungsband Wirtschaftinformatik, Zürich

Hevner AR, March ST, Park J, Ram S (2004) Design science in information systems research. Manage Inf Syst Q 28(1):75-105

Hofstede GH (1980) Culture's consequences: international differences in work related values. Sage, Beverly Hills

Hofstede GH, Bond MH (1998) The Confucius connection: from cultural roots to economic growth. Organ Dyn 16(4):4-21

Hofstede G, Hofstede GJ, Minkov M (2010) Cultures and organizations: software of the mind, 3rd edn. McGraw-Hill, New York

Holmstrom H, O'Conchuir E, Agerfalk PJ, Fitzgerald B (2006) Global software development challenges: a case study on temporal, geographical and socio-cultural distance. In: Proc int conf on global software engineering, Costão do Santinho
House RJ, Javidan M (2004) Overview of GLOBE. In: House RJ, Hanges PJ, Javidan M, Dorfman PW, Gupta V (eds) Overview of GLOBE. Sage, Thousand Oaks, pp 9-18

House RJ, Wright NS, Aditya RN (1997) Crosscultural research on organizational leadership: measurement of cultural dimensions. In: Erez PC, Earley M (eds) Crosscultural research on organizational leadership: Measurement of cultural dimensions, New Lexington, San Francisco, pp 571-581

Huang H, Trauth EM (2008) Cultural influences on temporal separation and coordination in globally distributed software development. In: Proc international conf on information systems, Paris

Huo YP, Randall DM (1991) Exploring subcultural differences in Hofstede's value survey: the case of the Chinese. Asia Pac J Manage 8(2):159-173

Hunter MG, Beck JE (2000) Using repertory grids to conduct cross-cultural information systems research. Inf Syst Res 11(3):93-101

Ishii K (2004) Internet use via mobile phone in Japan. Telecommun Policy 28(1):43-58

Kankanhalli A, Tan BCY, Wei K-K, Holmes MC (2004) Cross-cultural differences and information systems developer values. Decis Support Syst 38(2):183-195

Karahanna E, Evaristo JR, Srite M (2005) Levels of culture and individual behavior: an investigative perspective. J Glob Inf Manag 13(2):1-20

Kaye GR, Little S (2000) Dysfunctional development pathways of information and communication technology: cultural conflicts. J Glob Inf Manag 8(1):186-203

Keil M, Im GP, Mähring M (2007) Reporting bad news on software projects: the effects of culturally constituted views of face-saving. Inf Syst J 17(1):237-264

Keil M, Tan BCY, Wei K-K, Saarinen T, Tuuainen V, Wassenaar A (2000) A cross-cultural study on escalation of commitment behavior in software projects. Manage Inf Syst Q 24(2):299-325

Kelly GA (1955) The psychology of personal constructs. Norton, New York

Kelly GA (1963) A theory of personality. Norton, New York

Kersten G (2002) Do e-business systems have culture and should they have one? In: 10th proc European conf on information systems, Gdansk

Kersten E, Matwin S, Noronha SJ, Kersten MA (2000) The software for cultures and the cultures in software. In: 8th proc European conf on information systems, Wien

Kersten GE, Kersten MA, Rakowski WM (2002) Software and culture: beyond the internationalization of the interface. J Glob Inf Manag 10(4):86-101

Kim CS, Peterson DK (2002) Cultural differences in developers' perceptions of information systems success factors: Japan vs. the United States. J Glob Inf Manag 10(2):5-13

Kroeber AL, Kluckhohn C (1952) Culture: a critical review of concepts and definitions. Peabody Museum, Cambridge

Kumar K, Bjorn-Andersen N (1990) A crosscultural comparison of IS designer values. Commun ACM 33(5):528-538

Leidner DE, Kayworth T (2006) A review of culture in information systems research: towards a theory of information technology culture conflict. Manage Inf Syst Q 30(2):357-399

Leimeister S, Leimeister JM, Knebel U, Krcmar $\mathrm{H}$ (2009) A cross-national comparison of perceived strategic importance of RFID for 
CIOs in Germany and Italy. Int J Inf Manag 29(1):37-47

Loebbecke C, Thaller M (2005) Preserving Europe's cultural heritage in the digital world. In: 13th proc European conf on information systems, Regensburg

Marcus A, Gould EW (2000) Crosscurrents: cultural dimensions and global Web userinterface design. Interactions 7(4):32-46. doi:10.1145/345190.345238

Martinsons MG, Ma D (2009) Sub-cultural differences in information ethics across China: focus on Chinese management generation gaps. J Assoc Inf Syst 10(11):817-833

Monod E, Klein HK (2005) From eheritage to interpretive archaeology systems (IAS): a research framework for evaluating cultural heritage communication in the digital age. In: 13th proc European conf on information systems, Regensburg

Moores TT, Gregory FH (2000) Cultural problems in applying SSM for IS development. J Glob Inf Manag 8(1):14-19

Motwani J, Akbulut AY, Gleich R, Wald A (2007) Erfolgreiche ERP-Einführungen - eine kulturvergleichende Betrachtung. HMD, Prax Wirtsch.inform 44(256):105-112

Myers M, Tan F (2002) Beyond models of national culture in information systems research. J Glob Inf Manag 10(1):24-32

na (2008-2011) Profil der Wirtschaftsinformatik. http://wi.vhbonline.org/fileadmin/ Kommissionen/WK WI/Profil WI/Profil WI final_ds26

Peppas SC (2001) Subculture similarities and differences: an examination of US core values. Cross Cult Manage, An Int J 8(1):59-70

Peterson DK, Kim C (2003) Perceptions on IS risks and failure types: a comparison of designers from the United States. Jpn Kor J Global Inf Manag 11(3):19-38

Piccoli G, Ives B (2005) IT-dependent strategic initiatives and sustained competitive advantage: a review and synthesis of the literature. MIS Quarterly 29(4):747-776

Rai A, Maruping LM, Venkatesh V (2009) Offshore information systems project success: the role of social embeddedness and cul- tural characteristics. Manage Inf Syst Q 33(3):617-641

Ravesteyn P, Batenburg R (2010) Cultural differences in implementing business process management systems. In: 16th proc Americas conf on information Systems, Lima

Saab DJ (2008) An ethnorelative framework for information system design. In: 14th proc Americas conf on information systems, Toronto

Sarker S, Sarker S (2009) Exploring agility in distributed information systems development teams: an interpretive study in an offshoring context. Inf Syst Res 20(3):440-461

Stahlknecht P, Hasenkamp U (2004) Einführung in die Wirtschaftsinformatik, 11th edn. Springer, Berlin

Schein EH (2004) Organizational culture and leadership, 3rd edn. Jossey-Bass, San Francisco

Schreyögg G (1999) Organisation: Grundlagen moderner Organisationsgestaltung, 3rd edn. Gabler, Wiesbaden

Schwartz SH (1992) Universals in the content and structure of values: theoretical advances and empirical tests in 20 countries. In: Zanna $M$ (ed) Universals in the content and structure of values: theoretical advances and empirical tests in 20 countries. Academic Press, New York

Shanks G, Parr A, Hu B, Corbitt B, Thanasankit T, Seddon P (2000) Differences in critica success factors in ERP systems implementation in Australia and China: a cultural analysis. In: 8th proc European conf on information systems, Wien

Straub D, Loch K, Evaristo R, Karahanna E, Srite M (2002) Toward a theory-based measurement of culture. J Glob Inf Manag 10(1):13-23

Strauss W, Howe N (1991) Generations: the history of America's future. Quill William Morrow, New York, pp 1584-2089

Sun H (2001) Building a culturally-competent corporate Web site: an explanatory study of cultural markers in multilingual Web design. In: Northrop MJ, Tilley S (eds) Proc of the nineteenth annual ACM SIGDOC con- ference on computer documentation. ACM Press, New York, pp 95-102

Sydow J (1988) Der soziotechnische Ansatz der Arbeits- und Organisationsgestaltung: Darstellung, Kritik, Weiterentwicklung. Frankfurt, Campus

Tajfel H (1972) Social Categorization. In: Moscovici S (ed) Social categorization. Larousse, Paris, pp 272-302

Tajfel H, Turner J (1979) An integrative theory of intergroup conflict. In: Austin WG, Worchel $S$ (eds) An integrative theory of intergroup conflict. Brooks/Cole, Monterey, pp 33-47

Tan BCY, Smith $\mathrm{HJ}$, Keil M, Montealegre R (2003) Reporting bad news about software projects: impact of organizational climate and information asymmetry in an individualistic and a collectivistic culture. IEEE Trans Eng Manag 50(1):64-77

Triandis HC (1982) Dimensions of cultural variations as parameters of organizational theories. Int Stud Manag Organ 12(4):139169

Walsham G (2002) Cross-cultural software production and use: a structurational analysis. Manage Inf Syst O 26(4):359-380

Webster J, Watson RT (2002) Analyzing the past to prepare for the future: writing a literature review. Manage Inf Syst Q 26(2):1323

Wende E, Philip T (2011) Instant messenger in offshore outsourced software development projects: experiences from a case study. In: 44th proc Hawaii int conf syst sci, Hawaii

Winkler J, Dibbern J, Heinzl A (2007) Der Einfluss kultureller Unterschiede beim ITOffshoring: Ergebnisse aus Fallstudien zu deutsch-indischen Anwendungsentwicklungsprojekten. WIRTSCHAFTSINFORMATIK 49(2):95-103

Yuan M, Vogel D (2006) Cultural impact on intergroup coordination in software development in China: a qualitative analysis. In: 39th proc Hawaii int conf syst sci, Hawaii

Zahedi FM, VanPelt WV, Srite M (2006) Web documents' cultural masculinity and femininity. J Manag Inf Syst 26(1):87-128 